\title{
The influence of hygrothermal effects on the cross-ply composite laminate with transverse cracking in transient mode
}

\author{
Mohamed Khodjet-Kesba ${ }^{1, a}$, El Abbas Adda Bedia ${ }^{2}$, Amina Benkhedda $^{1}$, \\ BILlel Boukert ${ }^{1}$ AND TAHAR Rezoug ${ }^{1}$ \\ 1 Laboratoire des sciences aéronautiques, Institut d'aéronautique et des études spatiales, Université de Blida 1, Algérie \\ ${ }^{2}$ Laboratoire matériaux et hydrologie, université de Sidi Belabes, Algérie
}

Received 13 February 2015, Accepted 8 January 2016

\begin{abstract}
The stiffness reduction of symmetric hygrothermal cracked and aged cross-ply laminates is predicted by using two different models, shear-lag and variational approach. The material properties are considered to be dependent on temperature and transient moisture distribution in desorption case. This transient hygrothermal effect is taken into account to access the changes in the longitudinal modulus due to transverse cracking. The obtained results illustrate well the dependence of the stiffness degradation on the cracks density and transient environmental conditions, especially at high temperature. Through the presented study, we hope to contribute to the understanding of hygrothermal behaviour of cracked composite laminate.
\end{abstract}

Key words: Damage / stiffness reduction / transverse crack / hygrothermal aging / cross ply / moisture desorption

\section{Introduction}

In the case of cross-ply laminates submitted to uniaxial loading, the first damage which appears is often matrix cracking in the off-axis plies. It is clear, therefore, that the capability to predict the occurrence of transverse cracking and its effect on stiffness degradation is necessary in the design and utilization of cross-ply laminate. Matrix cracks and their effects on material properties degradation gained much attention both experimentally, numerically and analytically due to their practical importance.

Groves et al. [1], have examined experimentally the matrix cracking phenomenon in polymer composite crossply laminates. The first results show a degradation of the mechanical properties due to transverse cracks. Many analytical models have been developed which attempt to evaluate the stress distribution and the stiffness degradation due to transverse cracks. A more refined method is the shear lag method used by Berthelot et al. [2], Nairn and Mendels [3], Yokozeki and Aoki [4], and recently modified by Tounsi et al. [5], Adda Bedia et al. [6] by introducing the stress perturbation function. The simplicity of the method and the good accuracy are the strong points of this model. Another method based on the principal of minimum complementary potential energy is

\footnotetext{
${ }^{a}$ Corresponding author: mkhojet@hotmail.fr
}

the variational approach which was used by Hashin [7], Vinogradov et al. [8] Barbero and Cosso [9], Hajikazemi et al. [10], Katerelos et al. [11] This method can provide acceptable values, for upper and lower bounds of the stiffness.

A generalised plane strain model for the evaluation of the stress fields in $[0 / 90]_{\mathrm{s}}$ laminates, loaded in tension with a regular crack array in the $90^{\circ}$ ply was proposed by McCartney [12]. The in-plane stresses were considered constant through the thickness of each layer, and they were written as the sum of their nominal value, computed with a stress perturbation, function of the transverse coordinate of the $90^{\circ}$ ply and the Classical Lamination Theory (CLT). A fourth order differential equation was obtained for the stress perturbation function by solving the $2 \mathrm{D}$ equilibrium equations. The result was identic to that obtained by Hashin [7], a part from the fact that a generalised plane strain hypothesis was assumed by McCartney.

Crack-Faces-Displacement (CFD) models are based on the micromechanical theorem, which states that the global laminate strains can be computed by averaging the strains over the volume of each layer. By means of the divergence theorem it turns out that this process is equivalent to averaging the displacement components over the surfaces of each layer. Lundmark and Varna [13] have developed calculation scheme to predict stiffness reduction 


\section{Nomenclature}

\begin{tabular}{|ll|}
\hline$A_{0}(x)$ & Displacement parameter in the $0^{\circ}$ ply \\
$A_{90}(x)$ & Displacement parameter in the $90^{\circ}$ ply \\
$D_{z}$ & Diffusivity in the transverse direction \\
$E_{f x}$ & Young modulus of fibre in longitudinal direction \\
$E_{f y}$ & Young modulus fibre in transverse direction \\
$E_{m}$ & Young modulus of the matrix \\
$f(z)$ & Function of displacement \\
$v_{f x}$ & Poisson's ratio in the direction of the fibre \\
$v_{m}$ & Poisson's ratio of the matrix \\
$G_{f x}$ & Shear modulus of the fibre \\
$G_{m}$ & Shear modulus of the matrix \\
$g$ & Ratio temperature concentration \\
$h$ & Thickness of plate \\
$V_{f}$ & Volume of fibres \\
$E_{x}$ & Longitudinal Young's modulus damaged cross-ply \\
$E_{x 0}$ & Longitudinal Young's modulus undamaged \\
& cross-ply \\
$E_{0}$ & Young modulus of $0^{\circ}$-layer \\
$E_{90}$ & Young modulus of $90^{\circ}$-layer \\
$G_{0}$ & Shear modulus of $0^{\circ}$-layer \\
$G_{90}$ & Shear modulus of $90^{\circ}$-layer \\
$\eta_{t}$ & Transfer parameter of mechanical loading \\
& across the thickness of $0^{\circ}$-layer \\
$v_{0}$ & Poisson's ratio of $0^{\circ}$-layer \\
$v_{90}$ & Poisson's ratio of $90^{\circ}$-layer \\
$\sigma_{c}$ & Applied tensile stress \\
$\sigma_{x x}^{0}$ & Longitudinal stress of $0^{\circ}$-layer \\
$\sigma_{x x}^{90}$ & Longitudinal stress of $90^{\circ}$-layer \\
$\sigma_{0}$ & Applied stress in $0^{\circ}$-layer \\
$\sigma_{90}$ & Applied stress in $90^{\circ}$-layer \\
$t_{0}$ & Thickness of $0^{\circ}$-layer \\
$t_{90}$ & Thickness of $90^{\circ}$-layer \\
$t$ & Time \\
$T_{\mathrm{opr}}$ & Operational temperature \\
$T_{g}$ & Transition temperature \\
$T_{0 g}$ & Transition temperature to the reference \\
$T_{\mathrm{rm}}$ & temperature \\
$\varepsilon_{x x}^{0}$ & Average strain \\
$l_{0}$ & Half-length between two consecutive cracks \\
& Consecutive cracks standardized \\
\hline
\end{tabular}

in the entire crack density region. The degradation of thermo-elastic properties of a laminate strongly depends on the intralaminar crack surface opening and sliding during loading. Convergence has been proved to occur after a very small number of iterations, but the final result was not in satisfactory agreement with FE models.

Another method which uses to analyse the dependence of the COD (crack opening displacement) on the crack density based on the finite element model was used by Joffe and Krasnikovs [14], Singh and Talreja [15], Akula and Garnich [16]. This model has shown quite interesting results which converge accurately to the experimental data. Li et al. [17] presented a technique for modelling multidirectional laminates in the presence of regular crack arrays in multiple layers with no more than two different fibres orientations. The main disadvantage of this method is that it allows to model no more than two crack directions.

The increase of the moisture inside the composite materials at the time of absorption or desorption phase, can modify the mechanical properties of these structures, Han and Nairn [18], Shen and Springer [19]. Moreover, following to prolonged exposure in a wet atmosphere and at variable temperatures, the degradation of these properties with time under various conditions during the use of structures, can be more severe [20,21]. Recently, Amara et al. [22], Tounsi et al. [23,24] examined theoretically the changes of the longitudinal Young's modulus on a cracked composite, using the shear-lag method and Hashin model. The material properties are considered to be dependent on temperature and moisture. A simple hygrothermal model (with constant temperature and moisture), was used to predict the stiffness degradation on the transverse crack density. They concluded that the degradation of elastic properties depends on the cracks density and hygrothermal conditions.

In this paper, two analytical models have been studied and compared with experimental test [1]. The shear-lag model, modified by introducing the stress perturbation function and the variational approach, are used to predict the effect of transverse cracks on the longitudinal Young's modulus degradation. Then, the cross-ply laminates are initially exposed to the hygrothermal aging, and submitted to transient and non-uniform moisture concentration distribution, for desorption case. For that the model which will enable us to introduce ageing and to see its development on the fibre and matrix scales, is the transient Tsai model [25]. This model allows us to predict the best representation of hygrothermal effects, on cracked composite laminate, compared to other works already done [22-24].

\section{Analysis}

We consider a symmetric cross-ply laminate which is subjected to uniaxial loads. It is assumed that the $90^{\circ}$ ply has developed continuous intralaminar cracks in fibre direction which extend from edge to edge in $z$ direction (Fig. 1).

\subsection{Shear lag model}

In first-order shear deformation theory (FSDT), the distribution of the transverse shear stress with respect to the thickness coordinate is assumed constant. Thus, a shear correction factor, which is hard to find because it depends on many parameters as cited by Menaa et al. [26], is required to compensate error because of assumption in FSDT. Recently, new plate theories, based on nonlinear variation in the in-plane displacements through 


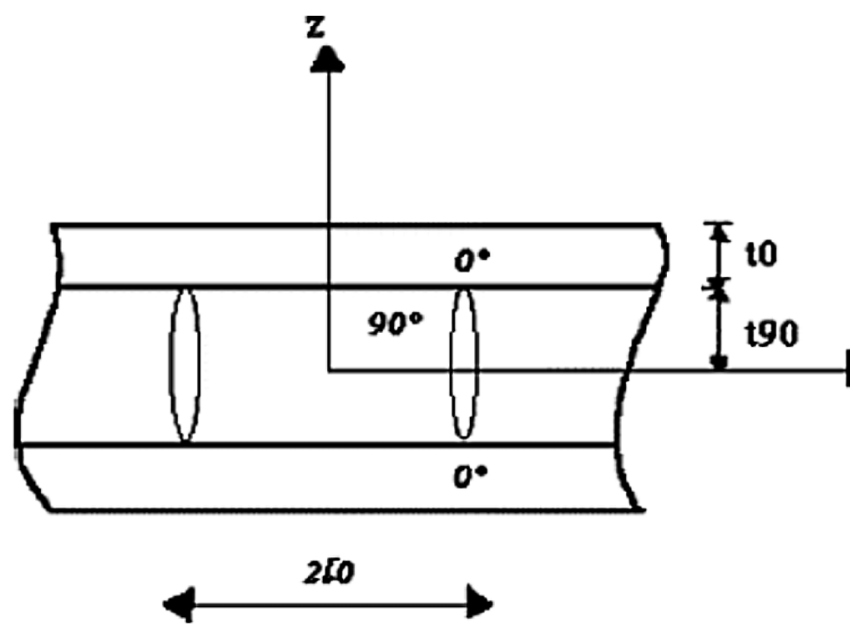

Fig. 1. Transverse cracked cross ply laminate and geometric model.

the thickness and do not require shear correction factor, are developed for plates by Tounsi et al. [27], Ait Yahia et al. [28], Ait Amar et al. [29], Belabed et al. [30], Bousahla et al. [31], Hebali et al. [32], and for beams by Bourada et al. [33], Ould Larbi et al. [34].

We have used in this study the model developed by Berthelot [2]. This later is modified by introducing the stress perturbation function. The axial stress is transferred by shear in thin layer. The longitudinal displacement in both layers $0^{\circ}$ plies and $90^{\circ}$ ply is [2]:

$$
\begin{aligned}
u_{0}(x, z) & =\overline{u_{0}}(x)+f(z) A_{0}(x) \\
u_{90}(x, z) & =\overline{u_{90}}(x)+\left(z^{2}-\frac{t_{90}^{2}}{3}\right) A_{90}(x)
\end{aligned}
$$

where $\overline{u_{0}}(x)$ and $\overline{u_{90}}(x)$ are the average longitudinal displacement in $0^{\circ}$ plies and the $90^{\circ}$ ply, respectively. $A_{0}(x)$, $A_{90}(x)$ and $f(z)$ to be determined.

The average longitudinal stresses in $90^{\circ}$ and $0^{\circ}$ layers are in the following forms:

$$
\begin{aligned}
& \overline{\sigma_{x x}^{90}}=\sigma_{c} \frac{E_{90}}{E_{x}^{0}}\left(1-\frac{\cosh \eta a \frac{x}{l}}{\cosh \eta a}\right) \\
& \overline{\sigma_{x x}^{0}}=\sigma_{c} \frac{E_{0}}{E_{x}^{0}}\left(1+\frac{t_{90} E_{90}}{t_{0} E_{0}} \frac{\cosh \eta a \frac{x}{l}}{\cosh \eta a}\right)
\end{aligned}
$$

with $a=\frac{l}{t_{90}}$ is the cracking aspect ratio and $\eta^{2}=$ $3\left(1+\frac{1}{\alpha}\right) \frac{G E_{x}^{0}}{E_{0} E_{90}}$ is the shear transfer parameter.

The longitudinal Young's modulus $E_{\mathrm{x}}$ of the crossply laminate relates the average stress $\sigma_{c}$ to the average longitudinal strain $\varepsilon_{c}$ of the laminate

$$
\sigma_{c}=E_{X} \varepsilon_{c}
$$

The average strain $\varepsilon_{c}$ is equal to average longitudinal strain of $0^{\circ}$-layer [2]:

$$
\varepsilon_{c} \approx \overline{\varepsilon_{x x}^{0}}=\frac{1}{l} \int_{0}^{l} \frac{\overline{\sigma_{x x}^{0}}}{E_{0}} \mathrm{~d} x
$$

The final expression of the longitudinal Young's modulus can be written as [2]:

$$
\frac{E_{x}}{E_{x}^{0}}=\frac{1}{1+\frac{t_{90}}{t_{0}} \frac{E_{90}}{E_{0}} \frac{1}{\eta a} \tanh \eta a}
$$

Two different analytical functions of the variation function have been considered [2]:

(a) A complete parabolic model with :

$$
f(z)=z^{2}-2\left(t_{0}+t_{90}\right) z+\frac{2}{3} t_{0}^{2}+2 t_{0} t_{90}+t_{90}^{2}
$$

(b) The variation of the longitudinal displacement is supposed progressive in $0^{\circ}$-layer with:

$$
f(z)=\frac{\sinh \alpha \eta_{t}}{\alpha \eta_{t}}-\cosh \eta_{t}\left(1+\alpha-\frac{z}{t_{90}}\right)
$$

\subsection{Variational approach}

There is another method, relatively simple, the variational approach [7], which satisfy equilibrium and all boundary and interface conditions to find an optimal approximation to the principle of minimum complementary energy. By assumption, normal stresses in load direction $\sigma_{x x}$ are constants depending on the thickness $(z)$ and the width $(y)$ in the $90^{\circ}$ and $0^{\circ}$ layers respectively and may be expressed in the form:

$$
\begin{aligned}
\sigma_{x x}^{90} & =\sigma_{90}\left(1-\phi_{1}(x)\right) \\
\sigma_{x x}^{0} & =\sigma_{0}\left(1-\phi_{2}(x)\right)
\end{aligned}
$$

$\phi_{1}(x)$ and $\phi_{2}(x)$ are unknown functions.

Next, we denote

$$
\phi_{1}(x)=\phi(x)
$$

And express $\phi_{2}(x)$ in term of $\phi(x)$ due to equilibrium condition in $x$ direction:

$$
\sigma_{0} t_{0} \phi_{1}(x)+\sigma_{90} t_{90} \phi_{2}(x)=0
$$

The final expression for complementary energy will be in form of:

$$
\begin{array}{r}
u_{c}^{\prime}=\frac{1}{2} \sigma_{90}^{2} t_{90}^{2} \int_{-a}^{+a}\left(C_{00} \phi^{2}+C_{02} \phi \frac{\mathrm{d}^{2} \phi}{\mathrm{d} \xi^{2}}+C_{22} \phi\left(\frac{\mathrm{d}^{2} \phi}{\mathrm{d} \xi^{2}}\right)^{2}\right. \\
\left.+C_{11}\left(\frac{\mathrm{d} \phi}{\mathrm{d} \xi}\right)^{2}\right) \mathrm{d} \xi
\end{array}
$$

where

$$
\begin{aligned}
C_{00} & =\frac{1}{E_{90}}+\frac{1}{\alpha E_{0}} \\
C_{02} & =\frac{v_{90}}{E_{90}}\left(\alpha+\frac{2}{3}\right)-\frac{\alpha v_{0}}{3 E_{0}} \\
C_{22} & =\frac{1}{60 E_{90}}(\alpha+1)\left(3 \alpha^{2}+12 \alpha+8\right) \\
C_{11} & =\frac{1}{3}\left(\frac{1}{G_{90}}+\frac{\alpha}{G_{0}}\right)
\end{aligned}
$$


The function $\phi$ which minimizes the complementary en$\operatorname{ergy} u_{c}^{\prime}$ is the fourth order differential equation of EulerLagrange:

$$
\frac{\mathrm{d}^{4} \phi}{\mathrm{d} \xi^{4}}+p \frac{\mathrm{d} \phi^{2}}{\mathrm{~d} \xi^{2}}+q \phi=0
$$

where

$$
p=\frac{C_{02}-C_{11}}{C_{22}} \text { and } q=\frac{C_{00}}{C_{22}}
$$

when $4 q>p^{2}$

Then the final solution is:

$$
\phi=A_{1} \operatorname{ch} \alpha a \frac{x}{l} \cos \beta a \frac{x}{l}+A_{2} \operatorname{sh} \alpha a \frac{x}{l} \sin \beta
$$

$A_{1}$ and $A_{2}$ are determined by the boundary conditions:

and $\alpha=q^{1 / 4} \cos \theta / 2 \beta=q^{1 / 4} \sin \theta / 2 \theta=\operatorname{arctg} \sqrt{\frac{4 q}{p^{2}}-1}$

The stiffness reduction $E_{x}$ can be expressed by [7]:

$$
\frac{E_{x}}{E_{x 0}}=\frac{1}{1+\frac{E_{90}}{E_{0}} \frac{t_{90}}{t_{0}} \frac{1}{\overline{l_{0}}} g\left(\overline{l_{0}}\right)}
$$

where $g\left(\overline{l_{0}}\right)$ is expressed by:

$$
g\left(\overline{l_{0}}\right)=\frac{2 \delta \beta}{\delta^{2}+\beta^{2}} \frac{\cosh \left(2 \delta \overline{l_{0}}\right)-\cos \left(2 \beta \overline{l_{0}}\right)}{\delta \sin \left(2 \beta \overline{l_{0}}\right)+\beta \sinh \left(2 \delta \overline{l_{0}}\right)}
$$

\section{Hygrothermal aging model}

The study, here has been focused on the stiffness reduction due to transverse ply cracking in cross ply laminate, when this latter is initially exposed to the transient hygothermal aging. Graphite/epoxy composite material [25] was selected in the present example. Tsai [25] proposes the adimensional temperature $T^{*}$, which is the essential parameter for evaluation of the hygrothermal effect in stress distribution:

$$
T^{*}=\frac{T_{g}-T_{\mathrm{opr}}}{T_{g}-T_{\mathrm{rm}}}
$$

We further assume that moisture suppresses the glass transition temperature by simple temperature shift.

$$
T_{g}=T_{g}^{0}-g c
$$

Let us consider a laminated plate of thickness $h$ made of polymer matrix composite, submitted on it two sides to the same dry environment. The plate is considered to be infinite in both $x$ and $y$ directions and the moisture varies only in the $z$ direction. The initial moisture concentration $C_{\text {init }}$ is uniform at $t=0$. Both sides of the plate are suddenly exposed to a zero moist environment (Fig. 2). The moisture concentration inside the plate is described by Fick equation with diffusivity $D_{z}$.

$$
\frac{\partial C}{\partial t}=D_{z} \frac{\partial^{2} C}{\partial z^{2}}
$$

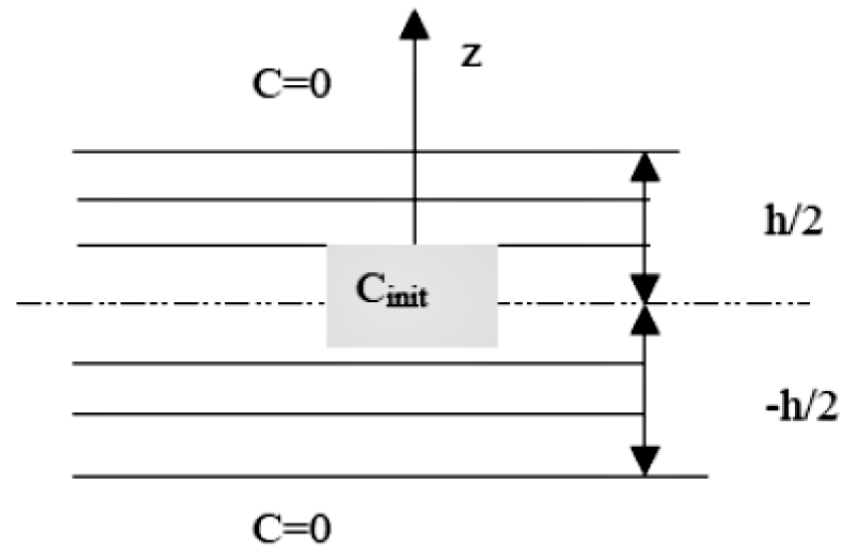

Fig. 2. Desorption phase.

with the initial conditions:

$$
\begin{aligned}
& C=C_{\text {init }} \text { for }-h / 2 \leq z \leq h / 2 \text { and } t=0 \\
& C=0 \text { for } z=-h / 2 ; z=h / 2, \text { and } t>0
\end{aligned}
$$

The initial conditions being uniform and the boundary conditions are constants. The unidimensional solution of Fick equation can be expressed as [35]:

$$
\begin{array}{r}
C\left(z_{k}, t\right)=\left[\frac{4 C_{\text {ini }}}{\prod} \sum_{n=0}^{\infty} \frac{(-1)^{n}}{(2 n+1)} \cos \left(\frac{(2 n+1) \prod z_{k}}{h}\right)\right. \\
\left.\times \exp \left(\frac{-D_{z}(2 n+1)^{2} \prod^{2} t}{h^{2}}\right)\right]
\end{array}
$$

\section{Results and discussion}

\subsection{Reduction of longitudinal Young's modulus}

In this section, we will validate the results without taking into account the hygrothermal effect on the material properties. The results are compared with experimental data for graphite/epoxy AS4-3502, where the material properties are summarized in Table 1.

The reduction of stiffness due to the transverse crack for AS/3502 laminate is shown in Figures 3 and 4. The figures exhibit the comparison between the analytical models and the experimental data (Groves et al. 1987). It can be seen that good agreement is obtained between the shear-lag model and experimental data. On the other hand, the variational approach gives greater reduction than the experimental tests [1]. Finally, it can be deduced that the reduction of stiffness is higher as we have more $90^{\circ}$ layers in laminates.

\subsection{Influence of hygrothermal conditions on the reduced stiffness}

The stiffness reduction is represented in cracked cross ply laminate exposed to hygrothermal conditions. Two 
Table 1. Material properties of composite AS4-3502 systems used in calculations [36].

\begin{tabular}{cccccccc}
\hline $\begin{array}{c}\text { Properties } \\
\text { Material }\end{array}$ & $\begin{array}{c}E_{0} \\
(\mathrm{GPa})\end{array}$ & $\begin{array}{c}E_{90} \\
(\mathrm{GPa})\end{array}$ & $\begin{array}{c}G_{0} \\
(\mathrm{GPa})\end{array}$ & $\begin{array}{c}G_{90} \\
(\mathrm{GPa})\end{array}$ & $v_{0}$ & $v_{90}$ & $\begin{array}{c}t_{0} \\
(\mathrm{~mm})\end{array}$ \\
\hline AS4-3502 & 144.8 & 9.58 & 4.79 & 4.2 & 0.31 & 0.4 & 0.127 \\
\hline
\end{tabular}

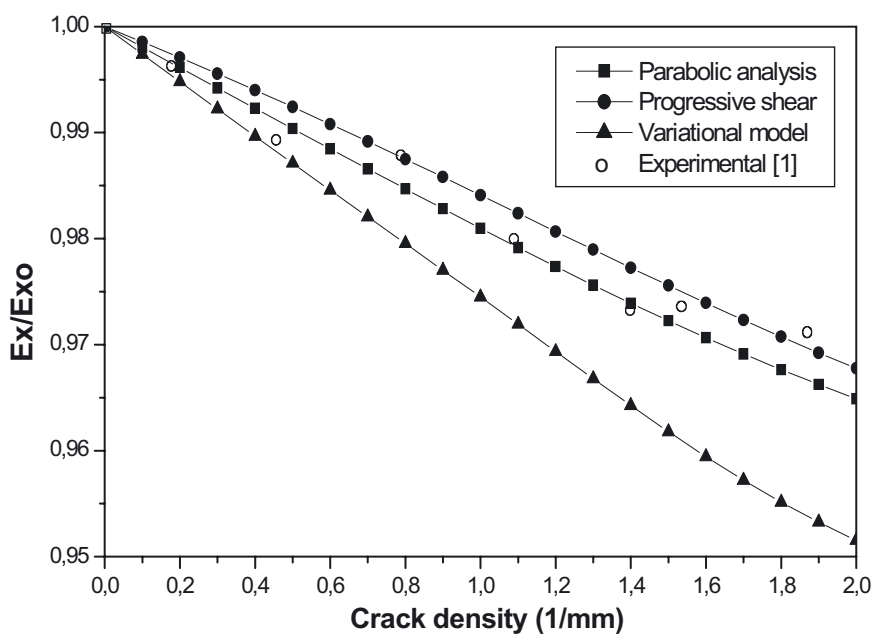

Fig. 3. Longitudinal Young's modulus degradation due to transverse cracks in a $[0 / 90]_{\mathrm{s}} \mathrm{AS} / 3502$ laminate.

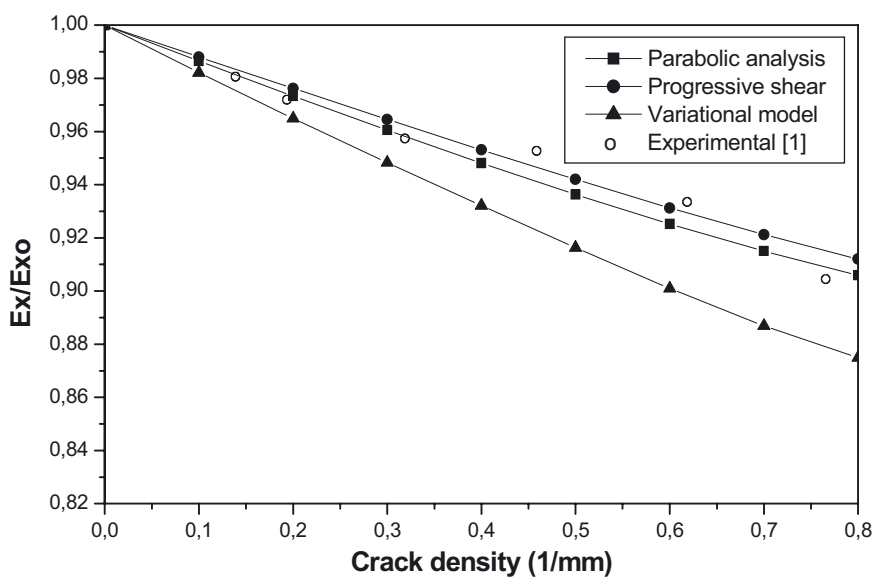

Fig. 4. Longitudinal Young's modulus degradation due to transverse cracks in a $\left[0 / 90_{3}\right]_{\mathrm{S}} \mathrm{AS} / 3502$ laminate.

different hygrothermal modes, uniform and transient moisture concentration have been selected, to represent the effect of temperature and moisture in the cracked cross-ply laminates. The time chosen for simulation is taken equal to $t_{\text {sat }}$, with $t_{\text {sat }}$ equal to $4222 \mathrm{~h}$, and is the moisture saturation for T300/5208. The characteristics of fibre and matrix of graphite/epoxy (T300/5208) $\left[0 / 90_{3}\right]_{\mathrm{s}}$ laminate are exposed in Table 2.

\subsection{Moisture effect on normalized axial modulus}

The loss of stiffness in the laminate as of crack density is evaluated compared to the initial stiffness of the same uncracked laminate and for the same environmental case.
Table 2. Fiber and matrix characteristics of graphite/epoxy material (T300/5208) [36].

\begin{tabular}{cccccccc}
\hline $\begin{array}{c}E_{f x} \\
(\mathrm{Gpa})\end{array}$ & $\begin{array}{c}E_{f y} \\
(\mathrm{Gpa})\end{array}$ & $\nu_{f x}$ & $\begin{array}{c}E_{m} \\
(\mathrm{Gpa})\end{array}$ & $\nu_{m}$ & $\begin{array}{c}G_{m} \\
(\mathrm{Gpa})\end{array}$ & $\begin{array}{c}G_{f x} \\
(\mathrm{Gpa})\end{array}$ & $V_{f}$ \\
\hline 259 & 18.69 & 0.25 & 3.4 & 0.35 & 1.26 & 19.69 & 0.7 \\
\hline
\end{tabular}

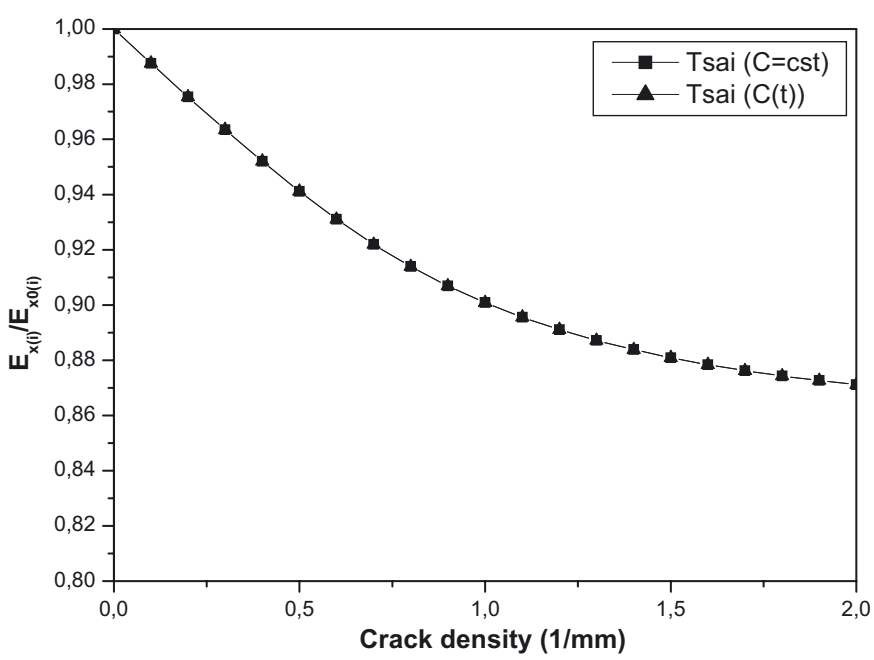

Fig. 5. Moisture effect on the longitudinal Young's modulus degradation due to transverse cracks in a $\left[0 / 90_{3}\right]_{\mathrm{s}}$ Graphite/epoxy laminate T300/5208 $\left(T_{\mathrm{op}}=22{ }^{\circ} \mathrm{C}\right.$ and $C=$ $0.5 \%)$.

We note that this initial stiffness of the uncracked laminate is function of temperature and moisture distribution. Consequently, Equations (7) and (23) become:

$$
\begin{aligned}
& \frac{E_{x(i)}}{E_{x(i)}^{0}}=\frac{1}{1+\frac{t_{90}}{t_{0}} \frac{E_{90(i)}}{E_{0(i)}} \frac{1}{\eta_{(i)} a} \tanh \eta_{(i)} a} \\
& \frac{E_{x(i)}}{E_{x(i)}^{0}}=\frac{1}{1+\frac{E_{90(i)}}{E_{0(i)}} \frac{t_{90}}{t_{0}} \frac{1}{l_{0}} g_{(i)}\left(\overline{l_{0}}\right)}
\end{aligned}
$$

The index $(i)$ represents the considered case of the environmental conditions.

The obtained results are reported in Figures 5 to 7 using a parabolic variation of longitudinal displacement in both $0^{\circ}$ and $90^{\circ}$ layers. The longitudinal Young's modulus is represented with two different hygrothermal models, uniform concentration, and transient moisture distribution in desorption case. The results show that the moisture has no effect on the normalized axial modulus. Only the crack density influences this latter. 


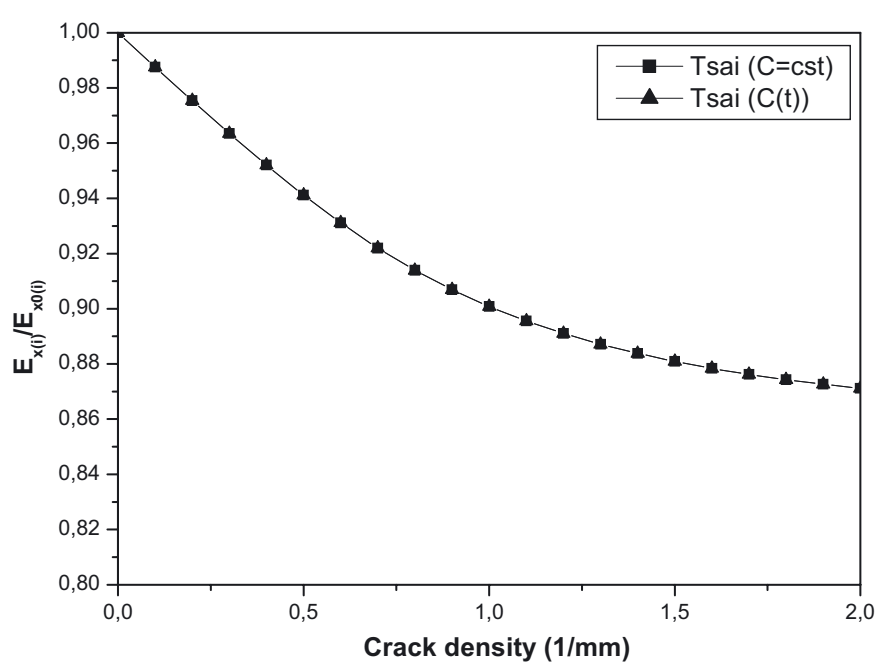

Fig. 6. Moisture effect on the longitudinal Young's modulus degradation due to transverse cracks in a $\left[0 / 90_{3}\right]_{\mathrm{s}}$ Graphite/epoxy laminate T300/5208 $\left(T_{\text {op }}=22{ }^{\circ} \mathrm{C}\right.$ and $C=$ $1 \%)$.

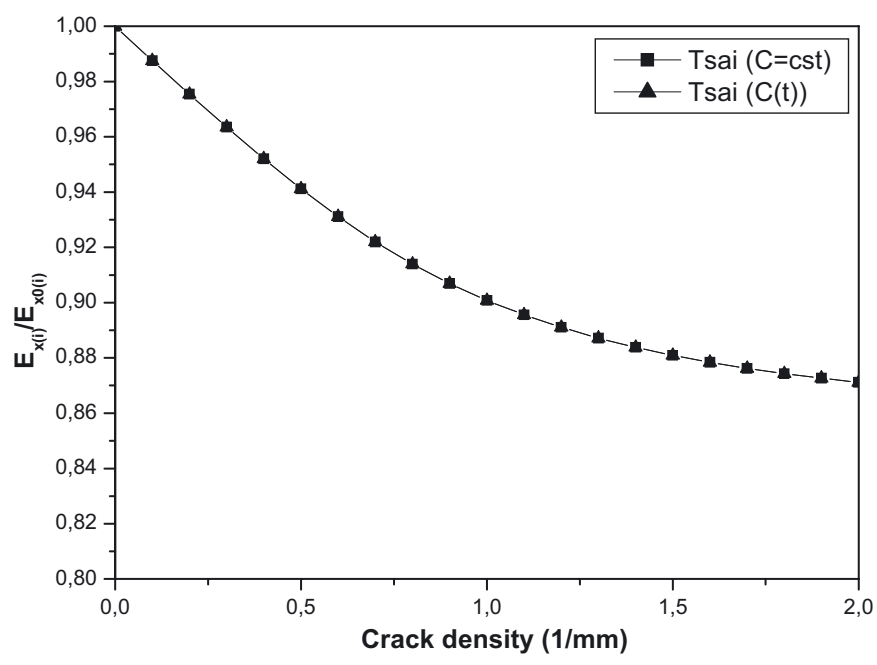

Fig. 7. Moisture effect on the longitudinal Young's modulus degradation due to transverse cracks in a $\left[0 / 90_{3}\right]_{\mathrm{s}}$ Graphite/epoxy laminate T300/5208 $\left(T_{\text {op }}=22{ }^{\circ} \mathrm{C}\right.$ and $C=$ $1.5 \%)$.

\subsubsection{Temperature effect on normalized axial modulus}

In the same as presented above, two sets of environmental conditions are considered. For environmental case $1, T_{\text {op }}=60^{\circ}$ and for environmental case $2, T_{\text {op }}=120^{\circ}$. In the two cases, the moisture is supposed to be equal to $C=1.5 \%$. The results in Figures 8 and 9 show that starting from $T_{\mathrm{op}}=60{ }^{\circ} \mathrm{C}$, a little difference is noticed between transient Tsai model and Tsai. Increasing the operational temperature, the transient Tsai model gives more reduction of the relative stiffness, especially at high crack density.

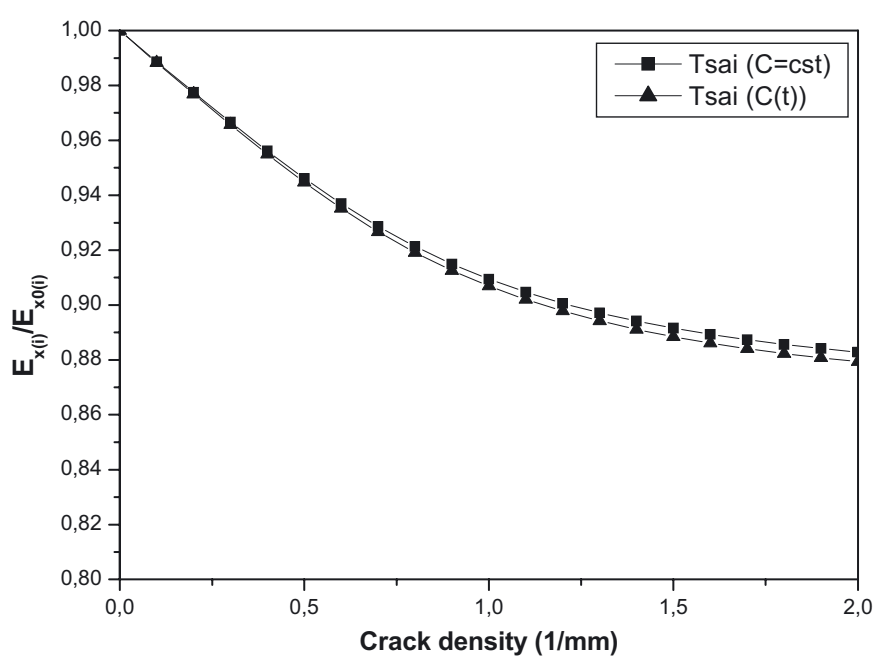

Fig. 8. Temperature effect on the longitudinal Young's modulus degradation due to transverse cracks in a $\left[0 / 90_{3}\right]_{\mathrm{s}}$ Graphite/epoxy laminate T300/5208 $\left(T_{\mathrm{op}}=60{ }^{\circ} \mathrm{C}\right.$ and $C=$ $1.5 \%$ ).

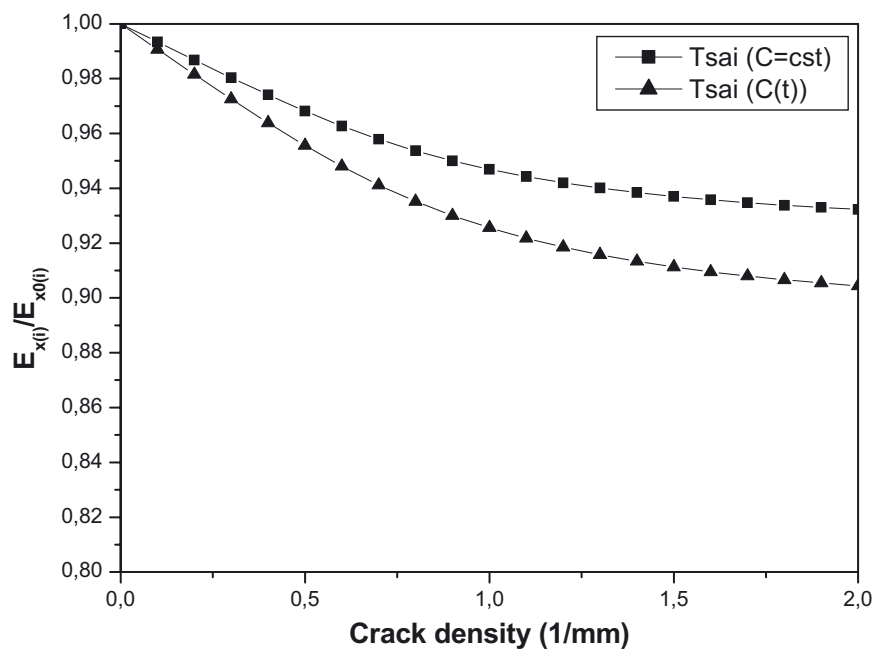

Fig. 9. Temperature effect on the longitudinal Young's modulus degradation due to transverse cracks in a $\left[0 / 90_{3}\right]_{\mathrm{s}}$ Graphite/epoxy laminate T300/5208 $\left(T_{\mathrm{op}}=120{ }^{\circ} \mathrm{C}\right.$ and $C=1.5 \%$ ).

\section{Conclusion}

Different analytical models have been proposed, to predict the effect of transverse cracks on the stiffness reduction of hygrothermal aged composite laminates. The material properties are considered to be dependent on temperature and moisture distribution, which are given explicitly in terms of the fibre and matrix properties and fibre volume ratio. The result shows that the moisture has no effect on the normalized axial modulus. However, at high temperatures, the transient Tsai model gives more reduction of the relative stiffness than obtained with uniform moisture concentration. For that, in desorption case, the chosen material will be weaker at high crack density and hygrothermal conditions. Finally, at 
high environmental conditions, the transient Tsai model seems more accurate to predict the true hygrothermal behaviour of cracked cross-ply laminates.

\section{References}

[1] S.E. Groves, C.E. Harris, A.L. Highsmith, D.H. Allen, R.G. Norvell, An experimental and analytical treatment of matrix cracking in cross-ply laminates, Exp. Mech. 27 (1987) 73-79

[2] J.M. Berthelot, P. Leblonb, El mahi, J.F. Le core, Transverse cracking of cross ply laminates: part Analysis, Composites A 27 (1996) 989-1001

[3] J.A. Nairn, D.A. Mendels, On the use of planar shearlag methods for stress transfer analysis of multilayered composites, Mech. Mater. 33 (2001) 335-362

[4] T. Yokozeki, T. Aoki, Overall thermoelastic properties of symmetric laminates containing obliquely crossed matrix cracks, Compos. Sci. Technol. 65 (2005) 1647-1654

[5] A. Tounsi, K.H. Amara, A. Benzair, A. Megueni, On the transverse cracking and stiffness degradation of aged angle-ply laminates, Mater. Lett. 60 (2006) 2561-2564

[6] E.A. Adda-bedia, M. Bouazzaa, A. Tounsi, A. Benzair, M. Maachou, Prediction of stiffness degradation in hygrothermal aged $\left[\theta_{\mathrm{m}} / 90_{\mathrm{n}}\right]_{\mathrm{s}}$ composite laminates with transverse cracking, J. Mater. Process. Technol. 199 (2008) 199-205

[7] Z. Hashin, Analysis of cracked laminates: a variational approach, Mech. Mater. 4 (1985) 121-136

[8] V. Vinogradov, Z. Hashin, Variational analysis of cracked angle-ply laminates, Compos. Sci. Technol. 70 (2010) 638-646

[9] E.J. Barbero, F.A. Cosso, Determination of material parameters for discrete damage mechanics analysis of carbon-epoxy laminates, Composites B 56 (2014) 638646

[10] M. Hajikazemi, M.H. Sadr, Stiffness reduction of cracked general symmetric laminates using a variational approach, Int. J. Solids Struct. 51 (2014) 1483-1493

[11] D.T.G. Katerelos, A. Krasnikovs, J. Varna, Variational models for shear modulus of symmetric and balanced laminates with cracks in $90^{\circ}$-layer, Int. J. Solids Struct. 71 (2015) 169-179

[12] L.N. McCartney, Theory of stress transfer in a $[0 / 90]_{\mathrm{s}}$ cross ply laminate containing a parallel array of transverse cracks, J. Mech. Phys. Solids 40 (1992) 27-68

[13] P. Lundmark, J. Varna, Stiffness reduction in laminates at high intralaminar crack density: effect of crack interaction, Int. J. Damage Mech. 20 (2011) 279-297

[14] R. Joffe, A. Krasnikovs, J. Varna, COD-based simulation of transverse cracking and stiffness reduction in $\left[\mathrm{S} / 90_{\mathrm{n}}\right]_{\mathrm{s}}$ laminates, Compos. Sci. Technol. 61 (2001) 637-656

[15] C.V. Singh, R. Talreja, A synergistic damage mechanics approach for composite laminates with matrix cracks in multiple orientations, Mech. Mater. 41 (2009) 954-968
[16] V.M.K. Akula, M.R. Garnich, Effective ply and constituent elastic properties for cracked laminates, Composite B 43 (2012) 2143-2151

[17] S. Li, C.V. Singh, R. Talreja, A representative volume element based on translational symmetries for FE analysis of cracked laminates with two arrays of cracks, Int. J. Solids Struct. 46 (2009) 1793-1804

[18] M.H. Han, J.A. Nairn, Hygrothermal aging of polyimide matrix composite laminates, Composites A 34 (2003) 979-986

[19] C.H. Shen, G. Springer, Moisture absorption and desorption of composite materials, J. Compos. Mater. 10 (1976) $2-20$

[20] M. Zidi, A. Tounsi, M.S.A Houari, E.A. Adda Bedia, O. Anwar, Bending analysis of FGM plates under hygrothermo-mechanical loading using a four variable refined plate theory, Aerosp. Sci. Technol. 34 (2014) 24-34

[21] F. Chattibi, K.H. Benrahou, A. Benachour, K. Nedri, A. Tounsi, Thermomechanical effects on the bending of antisymmetric cross-ply composite plates using a four variable sinusoidal theory, Steel Composite Struct. 19 (2015) $93-110$

[22] K. Amara, M. Bouazza, K. Antar, A. Megueni, Evaluation of the stiffness of composite materials with hygrothermal conditions, Leonardo J. Sci. 25 (2014) 5764

[23] A. Tounsi, K.H. Amara, E.A. Adda-dedia, Analysis of transverse cracking and stiffness loss in cross-ply laminates with hygrothermal conditions, Comput. Mater. Sci. 32 (2005) 167-174

[24] M. Bouazza, A. Tounsi, A. Benzair, E.A. Adda-dedia, Effect of transverse cracking on stiffness reduction of hygrothermal aged cross-ply laminates, Mater. Design 28 (2007) 1116-1123

[25] S.W. Tsai, Composite design, Think composite, 4th edition, Dayton, 1988

[26] R. Menaa, A. Tounsi, F. Mouaici, I. Mechab, M. Zidi, E. A. Adda Bedia, Analytical solutions for static shear correction factor of functionally graded rectangular beams, Mech. Adv. Mater. Struct. 19 (2012) 641-652

[27] A.Tounsi, M.S.A. Houari, S. Benyoucef, E.A. Adda Bedia, A refined trigonometric shear deformation theory for thermoelastic bending of functionally graded sandwich plates, Aerosp. Sci. Technol. 24 (2013) 209-220

[28] S. Ait Yahia, H. Ait Atmane, M.S.A. Houari, A. Tounsi, Wave propagation in functionally graded plates with porosities using various higher-order shear deformation plate theories, Struct. Eng. Mech. 53 (2015) 1143-1165

[29] M. Ait Amar, H.H. Abdelaziz, A. Tounsi, An efficient and simple refined theory for buckling and free vibration of exponentially graded sandwich plates under various boundary conditions, J. Sandwich Struct. Mater. 16 (2014) 293-318

[30] Z. Belabed, M.S.A. Houari, A. Tounsi, S.R. Mahmoud, O. Anwar Bég, An efficient and simple higher order shear and normal deformation theory for functionally graded material (FGM) plates, Composites B 60 (2014) 274-283 
[31] A.A. Bousahla, M.S.A. Houari, A. Tounsi, E.A. Adda Bedia, A novel higher order shear and normal deformation theory based on neutral surface position for bending analysis of advanced composite plates, Int. J. Comput. Methods 11 (2014) 1350082

[32] H. Hebali, A. Tounsi, M.S.A. Houari, A. Bessaim, E.A. Adda Bedia, A new quasi-3D hyperbolic shear deformation theory for the static and free vibration analysis of functionally graded plates, ASCE J. Eng. Mech. 140 (2014) 374-383

[33] M. Bourada, A. Kaci, M.S.A. Houari, A. Tounsi, A new simple shear and normal deformations theory for functionally graded beams, Steel Compos. Struct. 18 (2015) 409-423
[34] L. Ould Larbi, A. Kaci, M.S.A. Houari, A. Tounsi, An efficient shear deformation beam theory based on neutral surface position for bending and free vibration of functionally graded beams, Mechanics Based Design of Structures and Machines 41 (2013) 421-433

[35] A. Benkhedda, A. Tounsi, E.A. Adda Bedia, Effect of temperature and humidity on transient hygrothermal stresses during moisture desorption in laminated composite plates, Compos. Struct. 82 (2008) 629-635

[36] T. Rezoug, A. Benkhedda, M. Khodjet-kesba, E. Adda Bedia, Analysis of the composite patches cracked and aged in hygrothermal conditions, Mechanics and Industry 12 (2011) 395-398 